\title{
Uso de la imagen femenina en medios: Análisis de contenido de las portadas de revistas con presencia en redes sociales
}

The use of the female image in media: A content analysis of magazine covers with presence in social media

\section{Maria D. Brito-Rhor}

Universidad Juan Carlos, Madrid, España

Universidad San Francisco de Quito, Quito, Ecuador

mbritolusfq.edu.ec

\section{Resumen}

Para determinar el uso de la imagen femenina en las portadas de revistas de mayor tiraje del Ecuador se realizó un análisis de contenido psicolingüístico desde dos vertientes: indagación de los tipos de información sexual en la publicidad basado en la teoría de Courtney, Whipple y Reichert y la relevancia según el Modelo de Sperber y Wilson sobre el nexo léxico-semántico entre los textos y las imágenes referidas. Se examinaron las portadas en Facebook ( $n=392$ ): en el $45,7 \%$ hubo al menos una mujer, en el $18,1 \%$ al menos un hombre y en el $36,2 \%$ hubo ausencia humana. Además, en el $23,5 \%$ de las portadas hubo algún grado de desnudez y un $39,5 \%$ de sugerencia de erotismo. En las portadas en las que al menos hubo una mujer se halló que un 82,7\% contenía sugerencia de erotismo y se evidenció el uso de implicaturas a través de estímulos ostensivos hasta de $79,5 \%$.

Palabras Clave: imagen femenina en medios, revistas, sexo en la publicidad

\begin{abstract}
In order to determine the use of the female image on the covers of major magazines in Ecuador, I conducted an analysis of psycholinguistic content under two perspectives: exploring the types of sexual information in advertising based on the theory of Courtney, Whipple and Reichert and the relevance according to the Sperber and Wilson Model of the lexical-semantic nexus between the texts and the images implied. Facebook covers were examined $(n=392)$ : in $45.7 \%$ there was at least one woman, in $18.1 \%$ there was at least one man and in $36.2 \%$ there was no human at all. In addition, in $23.5 \%$ of the covers there was some degree of nudity and $39.5 \%$ suggests of eroticism. Regarding the covers in which there was at least one woman, $82.7 \%$ were found to contain a suggestion of eroticism and the use of implicatures through ostensive stimuli was evidenced up to $79.5 \%$.
\end{abstract}

Keywords: female image in media, magazines, sex in advertising 


\section{Introducción}

La comunicación humana es un hecho social complejo que depende, entre otros factores de la cognición, la cultura, las creencias y los hábitos comunicativos de los hablantes o usuarios de una lengua. En general la comunicación está estructurada bajo un principio de pertinencia, en la cual, los interlocutores buscan estar adecuados a la situación comunicativa. Sperber y Wilson (1996) afirman que la comunicación tiene éxito no cuando los oyentes reconocen el significado lingüístico de la expresión, sino cuando deducen de ésta el "significado" de lo que pretende expresar el emisor. Así, la pertinencia depende de que los interlocutores estén implícitamente de acuerdo en lo que persiguen expresar y además permanezcan en el mismo sistema de creencias culturales y lingüísticas.

Uno de los aspectos que trabaja la publicidad es el contexto comunicativo y desde el punto vista lingüístico es la pragmática la que se encarga de estudiar este contexto y explicar cómo funciona. Así, una de las teorías asociadas al ámbito pragmático es la Teoría de la Relevancia de Dan Sperber y Deirdre Wilson (1987) que aboga por un modelo inferencial de la comunicación y no solo el tradicional modelo del código, pensado como un proceso de codificación y decodificación. El proceso inferencial es más integral y complejo dado que las técnicas de estudio pragmático permiten el análisis de la semántica del enunciado en un contexto determinado.

En tal sentido, la publicidad se encarga de manejar la complejidad polisémica de la lengua y colocarla al servicio del mercado; tiene el poder de orientar, de manera intencionada, el pensamiento de su audiencia, sus percepciones sociales y culturales, alojadas en el "inconsciente colectivo" para entretejerlas con la riqueza semántica y pragmática de la lengua. La percepción del significado se vuelve entonces, en el ámbito publicitario, una metáfora de la realidad para inducir al consumo. Para lograr esto, la publicidad se sirve de múltiples tipos de apelativos que llevan al consumidor a crear ilusiones, situaciones ideales o idealizadas que crean tendencias en el consumo. Un tipo de apelativo es el sexual que es frecuentemente utilizado en la publicidad dirigida hacia el consumidor (Percy \& Rossiter, 1992). Como un mecanismo para llamar la atención de los consumidores, es muy común ver en la publicidad de los principales medios de comunicación el uso de estímulos sexuales (Hyllegard, Yan, Ogle, \& Attmann, 2010). Algunas investigaciones han señalado un aumento en el uso de estímulos sexuales dirigidos a mujeres (American Psychological Association, 2007). Además, se evidencia el uso de más modelos femeninas que aparecen con un grado evidente de desnudez y parejas en posiciones que sugieren relaciones sexuales (Zimmerman \& Dahlberg, 2008). Algunas cifras que demuestran este incremento en el uso de apelaciones sexuales en diferentes medios de comunicación son: $59 \%$ de los videos musicales muestran a las mujeres como estímulos sexuales (Zhang, Dixon, \& Conrad, 2010), 43\% de las mujeres vestían sexualmente en los anuncios publicitarios de revistas (Carpenter \& Reichert, 2004) y $41 \%$ de las mujeres en la televisión vestían ropa reveladora.

Pero, ¿cuáles son los valores o percepciones culturales de las que echa mano la publicidad en redes sociales en Ecuador? ¿Al día de hoy, es la imagen femenina el gran mecanismo ostensivo-inferencial que vende productos y del que se ha abusado? De acuerdo a una investigación realizada por BritoRhor, Rodríguez-Herráez \& Chachalo-Carvajal (2019) en Ecuador, las mujeres mostraron una actitud más feminista que la de los hombres ecuatorianos. Además, mientras mayor era el grado de desnudez que se utilizaba en el anuncio digital, la actitud ética era más negativa. Asimismo, se evidenció una actitud negativa más marcada hacia el anuncio que apelaba al sexismo hostil. Otro estudio realizado con mujeres ecuatorianas (Brito, 2019), concluyó que existe una relación positiva con el tipo de estímulo sexual utilizado (buen/mal gusto o más/menos intensol y la intención de compra. De ahí el tema central de análisis en este artículo la imagen femenina fija de las portadas en Facebook.

Sabemos que la publicidad evoluciona junto con el consumidor. Los tiempos que vivimos están sumergidos en el acceso a diferentes tecnologías de información, internet y redes sociales. De hecho, la red social Facebook contaba hasta marzo de 2018 con más de 2.2 billones de usuarios activos a nivel mundial de los cuales el Ecuador tenía más de 11 millones de usuarios registrados hasta diciembre de 2017 (Facebook IQ, 2018). Este universo de potenciales compradores no podía ser desaprovechado de ninguna manera, por lo que cualquier 
empresa que busque hacer llegar su marca al público se ha visto obligada a adaptarse y abrir nuevos canales de comunicación en redes sociales, que muestran como novedad la mayor interactividad con los posibles clientes y mayor inmediatez en las respuestas sobre sus preferencias u observaciones acerca del producto.

Con el objetivo de determinar el uso de la figura femenina en las revistas de mayor tiraje del Ecuador se realizó un análisis de contenido psicolingüístico desde dos vertientes: indagación de los tipos de información sexual en la publicidad basado en la teoría de Courtney, Whipple y Reichert y la relevancia según el Modelo de Sperber y Wilson sobre el nexo léxico-semántico entre los textos y las imágenes referidas.

\section{Revisión de la literatura}

\subsection{Apelaciones Sexuales en la Publicidad}

En la publicidad racional se revelan las características básicas del producto, sus particularidades y bondades. Además, se procura mostrar el producto haciendo que se convierta en una metáfora de sensaciones y emociones con base al contexto comunicativo del consumidor potencial. Al respecto, Martínez-Rodrigo y Sánchez-Martín (2011) citan a Sáez (2003) cuando afirman que la publicidad "nos propone una manera de entender los valores sociales en juego que será la forma de razonar que a ellos les conviene para convencernos de que, con los productos vamos a cumplir con la forma ideológica que inculcan" (p.471). A este respecto, una de las figuras que se usa y/o se idealiza hasta el abuso es el de la imagen femenina. En muchas ocasiones, la publicidad asocia la imagen femenina a la sexualidad.

De acuerdo con la Organización Mundial de la Salud (OMS/WHO), se define la sexualidad como "un aspecto central del ser humano a lo largo de toda la vida, que abarca el sexo, las identidades y roles de género, el erotismo, el placer, la intimidad, la reproducción y la orientación sexual" (Molina \& Tejada, 2017, p. 19). La palabra sexo tiene variados significados dependiendo del área de investigación en la que se la utilice. Los investigadores del sexo, psicólogos sociales y mercadólogos definen a la información sexual como un estímulo sexual al cual se le atribuye un significado sexual (Reichert \& Lambiase, 2012). Por otra parte, la publicidad en sí misma es una forma aplicada de persuasión que intenta: informar, posicionar, convencer, reforzar y diferenciar; para alcanzar variados objetivos como, por ejemplo, vender productos y/o servicios, mejorar la imagen de la marca, educar al público, entre otros (O'Guinn, Allen \& Semenik, 2012; Reichert \& Lambiase, 2012). Además, la publicidad tiene que ser pagada y difundida a través de diferentes medios de comunicación con el objetivo de persuadir (O'Guinn, Allen, \& Semenik, 2012). Un tipo de estímulo de marketing es el sexual y se lo define como mensajes en diferentes medios de comunicación que contienen información sexual. Uno de los propósitos del uso del estímulo sexual en publicidad es el de persuadir a los consumidores a comprar la marca. El sexo en la publicidad es el reflejo de la sexualidad en forma de desnudez, imágenes sexuales, insinuaciones y dobles sentidos (Carpenter \& Reichert, 2004). Algunas de las marcas globales que utilizan apelaciones sexuales como herramienta publicitaria son: Victoria's Secret, Dolce \& Gabana, Calvin Klein, Armani, Gucci, Tommy Hilfiger, entre otras (Reichert \& Lambiase, 2012).

De acuerdo con la definición de sexo y publicidad, las apelaciones sexuales son recursos persuasivos que contienen información sexual la cual está integrada con el mensaje general (Reichert, Heckler \& Jackson, 2001). El contenido sexual en la publicidad es diverso. Sin embargo, se lo podría definir como aquellos estímulos dentro del anuncio que la gente los interpreta como sexuales (Reichert \& Ramirez, 2000).

Los primeros indicios del uso de estímulos sexuales en la publicidad se remontan al año 1850. Las compañías de tabacos ya usaban mujeres desnudas en sus cajas como elemento diferenciador de las otras marcas (Goodrum \& Dalrymple, 1990). A lo largo de los años se ha hecho evidente que el uso del erotismo en la publicidad ha ido aumentando de tono y cada vez es más explícito. Es así que, por ejemplo, la publicidad de R\&G Corsets resultó censurada por algunos medios en 1898; y si la comparamos con los anuncios de hoy en día, éstos distan mucho en términos de explicitud sexual. La primera marca en violar el tabú de mostrar anuncios en medios masivos, mostrando glúteos y penes, fue Calvin Klein en 1983 con su campaña de ropa interior (Reichert \& Lambiase, 2012). 
En un estudio realizado por Reichert y Lambiase (2003) se revela que las apelaciones sexuales están dirigidas tanto a hombres como a mujeres. No obstante, una mayor proporción de anuncios con contenido sexual aparecen en revistas de hombres $(12 \%)$ comparado con los que aparecen en revistas de mujeres $(6 \%)$. Las apelaciones sexuales dirigidas hacia las mujeres se enfocan en el atractivo, el comportamiento y la estima. En cambio, las apelaciones sexuales enfocadas en el segmento masculino exaltan "más y mejor sexo". Adicionalmente, las imágenes en las que solo aparecen hombres fueron casi nulas en comparación con las imágenes que contienen solo mujeres $(45 \%)$ o parejas $(47 \%)$.

Comúnmente, el objetivo de aplicar la estrategia del mensaje creativo, haciendo uso de estímulos sexuales en la publicidad, es conseguir la conexión o asociación afectiva con el consumidor (O'Guinn, Allen \& Semenik, 2012). No obstante, existen investigaciones que señalan tanto los efectos positivos como los negativos en cuanto al rol que tienen las apelaciones sexuales en la publicidad.

El estímulo sexual en la publicidad debe ser congruente con la imagen de sí mismo, ya sea real o ideal, con el fin de servir de vínculo entre el espectador del anuncio y el producto anunciado (Wilson \& Moore, 1979). Por otra parte, de acuerdo a la teoría de la excitación, un anuncio con contenido sexual, debería provocar respuestas emocionales y fisiológicas que podrían ser detectadas por los latidos del corazón, los patrones de respiración, la respuesta galvánica de la piel, la dilatación de las pupilas y los movimientos oculares (Wilson \& Moore, 1979). A todas estas variables o características del consumidor, hay que acotar que los seres humanos poseemos un sistema de valores que fueron moldeados por nuestra cultura y creencias adquiridas del entorno en donde crecimos y nos desarrollamos y que, ciertamente, van a mediar la respuesta de las personas ante el estímulo sexual.

Un anuncio exitoso funciona porque crea una conexión entre el producto o servicio que se promueve y alguna necesidad o deseo que la audiencia percibe (Reichert \& Lambiase, 2012). A estas conexiones o vínculos se los llama "apelaciones" que usualmente pueden ser: lógicas o racionales y emocionales.
La respuesta emocional de un consumidor influye en su actitud tanto hacia la publicidad como hacia la marca (Lee, Lee \& Harrell, 2002). Las investigaciones evidencian que una apelación emocional en la publicidad llama más la atención; y, aumenta el atractivo del producto, del mensaje y del recuerdo de la marca (Hazlett \& Hazlett, 1999). Los publicistas utilizan varias apelaciones, positivas o negativas, con el fin de generar una respuesta emocional en el consumidor (O'Guinn, Allen \& Semenik, 2012). A lo largo de los años, los anunciantes han utilizado una variedad de apelaciones de publicidad como son: el miedo, el humor, el sexo, la música, la racionalidad, las emociones y la escasez (Baack \& Clow, 2007).

Las apelaciones sexuales en la publicidad hacen uso de la sexualidad en forma de desnudez, imágenes sexuales, insinuaciones y dobles sentidos. Son mensajes en diferentes medios de comunicación, que contienen información sexual, con el propósito de aumentar la efectividad de la publicidad, como por ejemplo, llamar la atención y persuadir la venta de la marca (Carpenter \& Reichert, 2004; Reichert \& Lambiase, 2012).

\subsection{Teoría de la Relevancia}

La Teoría de la Relevancia, que usaremos en este estudio para verificar el uso psicolingüístico que da la publicidad ecuatoriana al empleo de la imagen femenina, tiene su raíz en los estudios sobre pragmática de Grice, específicamente del Principio de Cooperación y sus correspondientes máximas: cualidad, cantidad, relación y modo (Grice, 1961). Sperber y Wilson (1996) parten para su teoría de la máxima de relación o de relevancia que propugna el modelo inferencial como un proceso cognitivo. Este proceso mental, como cualquier proceso biológico afirma Moya (2006) se realiza:

Empleando un esfuerzo o gasto de energía determinado en su ejecución, ese efecto del procesamiento de un enunciado (productivo e interpretativol es un factor negativo ya que cuanto más elevado sea el gasto de energía empleado, menor será el grado de relevancia del enunciado (p. 33). 
Así, un mensaje es relevante en términos de gradación directamente proporcional, es decir, es más relevante en tanto que esfuerzo de procesamiento cognitivo es menor y viceversa. A esto hay que agregar que el contexto no viene dado de antemano en su totalidad, sino que el interlocutor elige lo que le parezca relevante, que lo conduzca a una interpretación satisfactoria (para ambas partes) y que implique el menor esfuerzo cognitivo. De tal manera que texto y contexto se entremezclan en una macro-estructura, que según Van Dijk (1980) abarca dos funciones cognitivas que reducen e integran la información y, al mismo, tiempo la integran y reorganizan según su grado de relevancia.

¿Qué es relevante dentro de un proceso comunicativo? Wilson y Sperber (2004) nos aclaran este punto: "cualquier estímulo externo o representación interna que sirva de input de un proceso cognitivo podrá considerarse relevante para un sujeto en una ocasión determinada" (p.239). De tal forma que toda información que pueda ser reconocida como significativa y que, además, implique un grado de esfuerzo bajo, será relevante. En este punto, Wilson y Sperber (2004) distinguen entre explicaturas, proceso cognitivo en el cual se decodifica o entiende en primera instancia el significado del enunciado, e implicaturas, proceso cognitivo durante el cual se completa el significado del enunciado en función al contexto comunicativo del interlocutor. Estas implicaturas tendrán éxito a través de lo que se denominó estímulo ostensivo sobre el cual recae la presunción de relevancia óptima, es decir que se ve legitimado por el receptor en función a su contexto (cognitivo, cultural o de preferencias).

La publicidad se sirve de las implicaturas dado que se busca persuadir y hacerlo a partir de conceptos "universales" o comunes al contexto comunicativo del segmento de mercado al que se pretenda llegar de forma atrayente, que estimule el comportamiento del consumidor y produzca reacciones de alta relevancia con el menor esfuerzo.

\section{Metodología}

Con el objetivo de determinar el uso publicitario de la figura femenina en las revistas de mayor ti- raje del Ecuador, a saber: Vistazo, Hogar, Cosas, Ekos y América Economía. Se realizó un análisis de contenido objetivo, cuantitativo, sistemático y psicolingüístico desde dos vertientes: análisis de los estímulos sexuales reflejado en la desnudez y la sugerencia del erotismo y la relevancia del nexo pragmático-inferencial entre los textos y las imágenes referidas.

Para la elección de las revistas de mayor tiraje en el Ecuador se recopiló la información de diferentes directorios digitales que listaban a todas las revistas que circulaban en el país. Luego se visitó físicamente los principales puntos de distribución de revistas para confirmar que efectivamente estaban en el punto de venta y verificar si existía alguna otra revista que no estuviera listada en los directorios digitales consultados. Seguidamente se visitaron los sitios web de todas las revistas listadas para obtener la información sobre el número promedio anual de ejemplares que salieron a la venta desde el año 2012 hasta el 2017. Una vez que se contaba con el nombre de la revista con su respectivo tiraje o circulación promedio anual, se verificó que tengan presencia en la red social más grande del planeta, Facebook, y se eligió a las cinco revistas de mayor tiraje y que cubrían un tiraje de más de 1 millón de ejemplares al año. En la Tabla 1 se describen las cinco revistas elegidas para el análisis de esta investigación.

Todas las portadas publicadas en Facebook por las cinco revistas elegidas desde febrero del 2012 a diciembre del 2017 fueron analizadas (n=392; Vistazo 131. Hogar 88, Cosas 73, Ekos 79 y América Economía 21). Cuando existía la presencia de alguna mujer en las portadas recolectadas, se procedía a analizar si existía un enfoque de tipo sexual. Primeramente, se miraba la cantidad y el tipo de vestimenta: diaria, sugestiva, parcialmente desvestida o desvestida. Inmediatamente se analizaba la presencia de algún tipo de sugerencia del erotismo como: belleza física, contacto visual, expresión facial, postura y otros factores de tipo erótico-sexual (Tabla 2). Las portadas fueron codificadas por dos personas, previamente entrenadas, con educación universitaria de maestría y expertos en lingüista y marketing. Los dos trabajaron de manera independiente y todas las discrepancias fueron discutidas por los codificadores hasta llegar a un acuerdo. 
Tabla 1. Descripción de las revistas de mayor tiraje que circulan en el Ecuador

\begin{tabular}{|c|c|}
\hline Revista & Descripción \\
\hline 1. Vistazo & $\begin{array}{l}\text { Es la primera revista del Ecuador fundada en 1957. Con una trayectoria de más de } 60 \text { años } \\
\text { vienen ejerciendo un periodismo veraz, pluralista y frontal. Recoge los puntos de vista más } \\
\text { diversos de los hechos y personajes del acontecer nacional e internacional. } \\
\text { Cobertura: Nacional } \\
\text { Página Web: https://www.vistazo.com/ } \\
\text { Presencia en Facebook: https://www.facebook.com/revistavistazo }\end{array}$ \\
\hline 2. Cosas Ecuador & $\begin{array}{l}\text { Es una revista internacional que llegó a Ecuador en 1995. Con una trayectoria de más de } 20 \\
\text { años te acerca al glamour, al arte y la actualidad. ¡Si salió en COSAS, sí sucedió! COSAS tiene } \\
\text { presencia en Chile, Perú, Bolivia, Nicaragua y Ecuador. } \\
\text { Cobertura: Nacional } \\
\text { Página Web: https://cosas.com.ec/ } \\
\text { Presencia en Facebook: https://www.facebook.com/RevistaCosasEcuador }\end{array}$ \\
\hline 3. Hogar & $\begin{array}{l}\text { Es una revista femenina fundada en } 1964 \text {. Con una trayectoria de más de } 50 \text { años te acerca } \\
\text { al mundo de la moda, belleza, cocina, decoración, salud y mucho más para la mujer de hoy. } \\
\text { Cobertura: Nacional } \\
\text { Página Web: http://www.revistahogar.com/ } \\
\text { Presencia en Facebook: https://www.facebook.com/RevistaHogar }\end{array}$ \\
\hline 4. Ekos & $\begin{array}{l}\text { Es una revista de negocios, management, empresas y tecnología fundada en 1994. Con } \\
\text { una trayectoria de más de } 20 \text { años te brinda información estratégica y conocimiento } \\
\text { para la efectiva toma de decisiones gerenciales. } \\
\text { Cobertura: Nacional } \\
\text { Página Web: http://www.ekosnegocios.com } \\
\text { Presencia en Facebook: https://www.facebook.com/RevistaEkos/ }\end{array}$ \\
\hline $\begin{array}{l}\text { 5. América } \\
\text { Economía }\end{array}$ & $\begin{array}{l}\text { Desde } 1986 \text { analiza los negocios, la economía y las finanzas de América Latina. Con una tra- } \\
\text { yectoria de más de } 30 \text { años ha impactado en los ejecutivos tomadores de decisión de la región. } \\
\text { Tiene presencia en Chile, Perú, México, Brasil y Ecuador. } \\
\text { Cobertura: Nacional } \\
\text { Página Web: http:// www.americaeconomia.com } \\
\text { Presencia en Facebook: https://www.facebook.com/americaeconomia/ }\end{array}$ \\
\hline
\end{tabular}

Fuente: Elaboración propia.

Tabla 2. Tipos de información sexual en la publicidad propuestas por Reichert y Lambiase (2012)

\begin{tabular}{|l|l|}
\hline Tipo & Descripción \\
\hline 1. Desnudez (vestimenta) & $\begin{array}{l}\text { Se refiere al grado de desnudez, a la cantidad y al estilo de la vestimenta que lucen } \\
\text { los modelos. Ejemplos: se revelan partes del cuerpo como busto y/o piernas, brazos } \\
\text { y pechos musculosos, ropa ajustada o sexual, mini faldas, trasparencias, traje de } \\
\text { baño, ropa interior y/o se infiere desnudez. }\end{array}$ \\
\hline
\end{tabular}

\section{Sugerencia de Erotismo}

2.1. Comportamiento Sexual Comportamiento sexual individual o interpersonal. Ejemplos: postura, coqueteo, contacto visual, abrazos, besos, lenguaje corporal, entre otros.

2.2. Atractivo Físico

2.3. Referente Sexual

2.4. Embebidos sexuales
Nivel de belleza de los modelos en su rostro, su cabello, su físico y en general en su complexión.

Referencia a objetos o eventos que tienen un significado sexual. Además, facilitadores para el mensaje sexual como música, luces, entre otros.

Contenido que se lo puede interpretar como sexual en un nivel subconsciente. Ejemplos: palabras como sexo, imágenes pequeñas de genitales, partes del cuerpo, entre otros.

Fuente: Elaboración propia. 
Tabla 3. Resultados de los tipos de información sexual en la publicidad

\begin{tabular}{|c|c|c|c|c|c|c|c|}
\hline \multirow[t]{2}{*}{ Revista } & \multirow{2}{*}{$\begin{array}{l}\text { Tiraje Anual } \\
\text { Promedio }\end{array}$} & \multicolumn{2}{|l|}{ Facebook } & \multicolumn{2}{|l|}{ Género } & \multicolumn{2}{|c|}{ Información Sexual* } \\
\hline & & No. Fans & $\begin{array}{l}\text { No. } \\
\text { Cubiertas }\end{array}$ & $\begin{array}{l}\text { Al Menos } \\
\text { una Mujer \% }\end{array}$ & $\begin{array}{l}\text { Solo Hombre } \\
\%\end{array}$ & $\begin{array}{l}\text { Desnudez } \\
\%\end{array}$ & $\begin{array}{l}\text { Sugerencia } \\
\text { del Erotismo } \\
\%\end{array}$ \\
\hline Vistazo & 528.000 & 58.535 & 131 & 31,30 & 36,60 & 34,10 & 43,90 \\
\hline Cosas & 240.000 & 383.731 & 73 & 82,20 & 12,30 & 83,30 & 96,70 \\
\hline Hogar & 192.000 & 880.895 & 88 & 80,70 & 1,10 & 36,60 & 100,00 \\
\hline Ekos & 60.000 & 91.226 & 79 & 5,10 & 11,40 & 25,00 & 25,00 \\
\hline América Economía & 48.000 & 443.964 & 21 & 14,30 & 19,00 & 0,00 & 0,00 \\
\hline Total & 1.068 .000 & 1.858 .351 & 392 & $45,70 \%$ & $18,10 \%$ & $50,80 \%$ & $82,70 \%$ \\
\hline
\end{tabular}

*Análisis condicionado a la presencia de al menos 1 mujer en la portada.

\section{Resultados y conclusiones}

Luego de haber realizado el análisis de contenido de las 392 portadas de Facebook, los resultados fueron los siguientes: en el $45,7 \%$ se utiliza al menos una mujer, en el $18,1 \%$ aparece al menos un hombre y en un $36,2 \%$ de los anuncios no hay presencia de figura humana (Tabla 3). De esto se desprende que en el $23,5 \%$ de los anuncios hay algún grado de desnudez y también se evidenció un 39,5\% de sugerencia de erotismo.

Por otra parte, se constató el uso de implicaturas, es decir la interpretación no convencional, a través de estímulos ostensivos (uso notorio de la figura femeninal hasta de $79,54 \%$ en las portadas con presencia de al menos una mujer. De todo lo anterior se desprende que hay una relación significativa entre la revista elegida y su preferencia por escoger como modelos a mujeres, hombres o ninguno. Así, en Hogar $(82,02 \%)$ y Cosas $(79,45 \%)$ se usa mucho más la presencia femenina en comparación con las otras tres revistas cuyos porcentajes varían entre 16,27\% (Vistazo), 9.52\% (América Economía) y $2.53 \%$ (Ekos). En las revistas en las que al menos hubo una modelo mujer se halló que un $82,7 \%$ de las portadas contenía sugerencia del erotismo; en Hogar fue del $100 \%$, en Cosas fue del $96,7 \%$, en Vistazo $43,9 \%$, en Ekos 25\% y en América Economía 0\%.

Al mismo tiempo, se distorsiona la imagen femenina, usada como estímulo ostensivo de forma no adecuada con el significado general. Por otra parte, la relación mostrada entre significante-significadoreferente de los vocablos que acompañaban a las imágenes hace que el interlocutor de dichas portadas infiera un significado diferente al tradicional, lo que acentúa la distorsión de la imagen femenina. En las revistas Hogar y Cosas se observó el uso excesivo de la imagen femenina como estímulo ostensivoinferencial, es decir, que la revista o emisor produce un estímulo con la intención de que el lector o receptor los reciba con un conjunto de supuestos 0 implicaturas que no son explícitas.

Asimismo, se observó que en las portadas de Hogar y Cosas hubo distorsión de la imagen femenina en la relación significado-significante-referente conduciendo la implicatura hacia belleza, erotismo, sensualidad y lujo. Por otra parte, las revistas Vistazo, Ekos y América Economía hacen muy poco uso de la imagen femenina y de hacerlo, es de forma indirecta o soslayada.

En la imagen 1, que representa a la mayoría de las portadas analizadas de la revista Hogar, se puede observar que la única palabra que acompaña a la foto de una mujer bella es "Hogar". De acuerdo a la RAE, hogar es una familia o grupo de personas emparentadas que viven juntas. Es este caso, el significado tradicional de hogar no coincide con lo que se pretende comunicar. La presencia de una mujer cosificada sexualmente se evidencia a través de la inferencia de desnudez lvestimenta sexual: algo de desnudez, poca cantidad de ropa y el estilo de la vestimenta). Asimismo, hay sugerencia de erotismo a través del comportamiento sexual (contacto visual y lenguaje corporal) y del atractivo físico (nivel de belleza de su rostro, su cabello, su físico y en general su complexión). El receptor podría inferir que el hogar estaría solamente representado por una 
Imagen 1. Portada de Facebook de Revisa Hogar (julio 13, 2017)

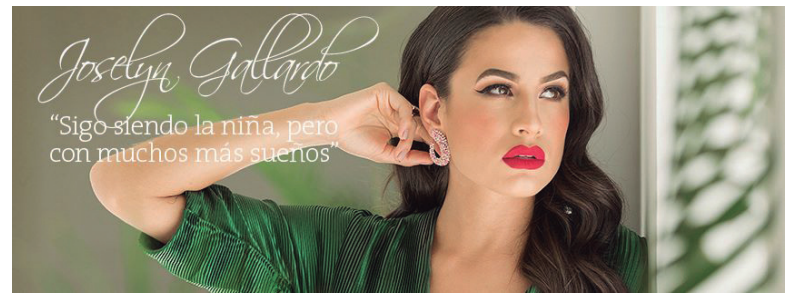

mujer bella y sexual. Esto dista mucho de lo que representa una mujer dentro de un hogar por lo tanto refuerza la distorsión de la imagen femenina.

En la imagen 2, de una de las portadas analizadas de la revista Cosas, se puede observar que el texto que acompaña a la foto de una mujer sexualmente bella es "Sigo siendo la niña, pero con muchos más sueños". De acuerdo a la RAE, la definición de niño/a se dice de una persona que no es un niño: que obra con poca reflexión o con ingenuidad o es una mujer que no ha perdido la virginidad. En este caso, el significado tradicional de niña tampoco coincide con lo que se pretende comunicar. La presencia de una mujer cosificada sexualmente se evidencia por la vía de la sugerencia de erotismo a través del comportamiento sexual (mirada sexual y lenguaje corporal) y del atractivo físico (nivel de belleza de su rostro, su cabello, su físico y en general su complexión). La correspondencia entre significante-significado-referente de la frase que acompaña a la imagen hace que el lector de dicha portada infiera un significado incomparable al tradicional, lo que realza la deformación de la imagen femenina.

Imagen 2. Portada de Facebook de Revisa Cosas (diciembre 22, 2017)

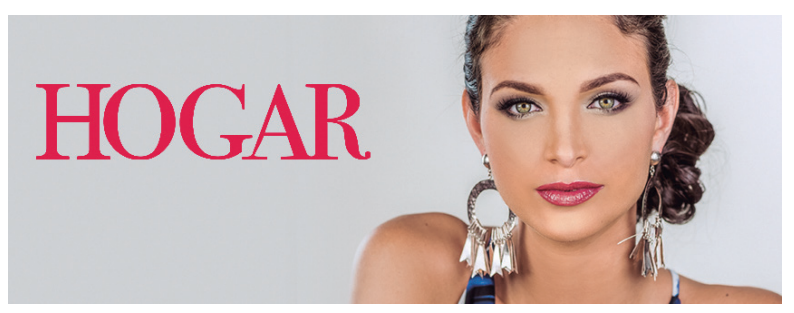

El rol de la mujer en los medios de comunicación no solo es el reflejo, sino que también refuerza estereotipos evidentemente sexistas en la sociedad. Los estereotipos de género son "el conjunto es- tructurado de creencias sobre las características - rasgos, conductas, actitudes, valores y normasque generalmente se piensa que son propias o deseables en la mujer o en el hombre" (Jato-Seijas, 2007, p. 160). Un área afectada es el mercado laboral en donde existe una diferenciación en las ocupaciones en cuando a género. Buena parte del trabajo femenino se agrupa en sectores cuyas funciones están relacionadas con los trabajos que las mujeres realizan en el ámbito doméstico y tan solo son una prolongación de éste (Navarro et al., 2016).

Definitivamente el uso de estímulos sexuales va a llamar la atención. Sin embargo, para que ésta sea una herramienta que incentive la intención de compra se la debe usar apropiadamente dentro del contexto. Mientras mayor es el grado de desnudez en el anuncio, la actitud ética de las personas es más negativa (Brito-Rhor et al., 2019). Es posible que si se excede la línea y se entra en territorio del sexismo se esté abusando en su uso y la marca se vea perjudicada y más bien cause efectos no deseados.

Los descubrimientos en la investigación sobre el uso y efectividad de las apelaciones sexuales en la industria publicitaria son contrastados. Sin embargo, existe un incremento en la utilización de dichos estímulos de índole sexual en diferentes espacios de la sociedad (Brito, 2019). La importancia de poner en evidencia que aún se usa y abusa de la imagen femenina, radica en el hecho de llamar a la reflexión a varias industrias en cuanto a su contribución a una sociedad libre de sexismo y machismo. Se debe erradicar la discriminación por razón de género y luchar por un mundo de igualdad de derechos. De acuerdo al informe global sobre las brechas de género publicado en el World Economic Forum (2018), hasta la fecha, la brecha de género promedio sigue siendo del $32,0 \%$. Proyectando las tendencias actuales hacia el futuro, la brecha global de género se cerrará en 108 años en los 106 países cubiertos desde la primera edición del informe. Las brechas de género más difíciles de cerrar son las dimensiones de empoderamiento económico y político, que, se estima, tardarán 202 y 107 años en cerrarse, respectivamente.

Como cualquier otra investigación, este estudio tiene algunas limitaciones. Se examina una muestra de revistas en Ecuador, así que los resultados podrían variar dependiendo del país estudiado. 
Adicionalmente, se investiga sobre el uso sexual de las mujeres en un ambiente digital, los resultados podrían también diferir si se analiza la versión impresa de la revista. Se recomienda que para futuras investigaciones se explore y compare otras revistas en diferentes países en formatos tanto físicos como digitales.

\section{Referencias}

American Psychological Association. (2007). Report of the APA Task Force on the Sexualization of Girls. Retrieved from http://www.apa.org/pi/women/programs/girls/ report-full.pdf

Baack, D., \& Clow, K. E. (2007). Integrated Advertising, Promotion, and Marketing Communications, 3rd Edition. Pearson, Prentice Hall, Woodland Hills, CA.

Brito-Rhor, M. D. (2019). El rol que tienen los estímulos sexuales en la publicidad digital desde una perspectiva fisiológica y psicológica. BURJC Digital. Retrieved November 20, 2019, from https://eciencia.urjc.es/handle/10115/16269.

Brito-Rhor, M. D., Rodríguez-Herráez, B., \& Chachalo-Carvajal, G. (2019). ¿Influye la intensidad de los estímulos sexuales y el feminismo en las actitudes de los consumidores hacia las apelaciones sexuales y el juicio ético? Una perspectiva ecuatoriana. Revista De Comunicación De La SEECI,0(48), 45. doi:10.15198/ seeci.2019.48.45-63

Carpenter, C., \& Reichert, T. (2004, Diciembre). An Update on Sex in Magazine Advertising: 1983 to 2003. Journalism \& Mass Communication, 81, 823-837.

Díaz, A. (julio-diciembre, 2011). La imagen metafórica publicitaria. Cuadernos de Lingüística Hispánica. (18). pp. 27-42

Goodrum, C. A., \& Dalrymple, H. (1990). Advertising in America: The First Two Hundred Years. New York.

Hazlett, R. L., \& Hazlett, S. Y. (1999). Emotional response to television commercials: Facial EMG vs self-report. Journal of Advertising Research 39 (2), 7-23.

Hyllegard, K., Yan, R., Ogle, J., \& Attmann, J. (2010). The influence of gender, social cause, charitable support, and message appeal on Gen Y's responses to cause-related marketing. Journal of Marketing Management, 27 (1/2), 100-123. doi:http:// dx.doi.org/10.1080/02672571003683755

Jato-Seijas, E. (2007). El desarrollo de la carrera profesional de las mujeres: particularidades y obstáculos. Revista Portuguesa de Pedagogía, 41(3), 151-171.

Lee, H., Lee, J., \& Harrell, G. D. (2002). Advertising=S longitudinal effect on brand and attitudes: The moderating roles of evaluation goals and attitude confidence. $A d-$ vances in Consumer Research 29, 173-179. 
Martínez-Rodrigo, E., \& Sánchez-Martín, L (Diciembre 2011) Publicidad en internet: Nuevas vinculaciones en las redes sociales. Revista de comunicación Vivat Academia. (XIV) 117E pp. 469-480

Molina, A., \& Tejada, A. (2017). Instrumentos de medida de actitudes hacia la sexualidad: Una revisión bibliográfica sistemática. Revista Iberoamericana de Diagnóstico y Evaluación - e Avaliação Psicológica, 1(43), 17-32. doi:https://doi.org/10.2

Moya, C. (2006) Relevancia e inferencia: Procesos cognitivos propios de la comunicación humana. : Forma y función [revista en línea]

Navarro-Astor, E., Román-Onsalo, M., \& Infante-Perea, M. (2016). Revisión internacional de estudios de barreras de carrera bajo la perspectiva de género en la industria de la construcción. Innovar, 26(61), 103-118. doi: 10.15446/innovar. v26n61.57169.

O'Guinn, T., Allen, C., \& Semenik, R. J. (2012). Advertising and Integrated Brand Promotion (6 ed., Vol. nn). (nn, Ed., \& nn, Trans.) Estados Unidos: South-Western Cengage Learning.

Percy, L., \& Rossiter, J. R. (1992). Advertising stimulus effects: A review. Journal of Current Issues and Research and Advertising(14), 75-90.

Reichert, T., \& Lambiase, J. (2003). How to get "kissably close": Examining how advertisers appeal to consumers' sexual needs and desires. Sexuality \& Culture, 7(3), 120-136. doi:http://dx.doi.org/10.1007/s12119-003-1006-6

Reichert, T., \& Lambiase, J. (2012). Sex in Advertising Perspectives on the Erotic Appeal. New Yorf: Routledge.

Reichert, T., \& Ramirez, A. (2000). Defining Sexually Oriented Appeals in Advertising: a Grounded Theory Investigation. Advances in Consumer Research Volume 27, eds. Stephen J. Hoch and Robert J. Meyer, Provo, UT : Association for Consumer Research, 267-273.

Reichert, T., Heckler, S. E., \& Jackson, S. (2001). The Effects of Sexual Social Marketing Appeals on Cognitive Processing and Persuasion. Journal of Advertising 30, 1327.

Sperber, D. \& Wilson, D. (1996). Relevance. Communication \& cognition (second edition) Oxford UK \& Cambridge USA: Backwell.

Trujillo, F. (2001) La teoría de la Relevancia como base para una nueva interpretación de la comunicación. Euphoros (3) pp. 221-232

Van Dijk, T. (1980) Texto y contexto. Semántica y pragmática del discurso. Madrid: Ediciones Cátedra

Varón, A. (2003) El contexto en la Teoría de la Relevancia. Humanities Research. Asociación de Humanidades de la Universidad de Kanagawa. (151) pp. 27-51

Wilson, R., \& Moore , N. K. (1979). The Role of Sexually-Oriented Stimuli in Advertising: Theory and Literature Review. In NA - Advances in Consumer Research Volume 06, eds. William L. Wilkie, Ann Abor, MI : Association for Consumer Research, 5561. Retrieved from http://acrwebsite.org/volumes/9530/volumes/v06/NA-06 
Wilson, D. \& Sperber, D. (2004) Teoría de la Relevancia. Revista de investigación lingüística. (VII) pp.237-286.

World Economic Forum: The Global Gender Gap Report 2018. (n.d.). Retrieved from http:// www3.weforum.org/docs/WEF_GGGR_2018.pdf

Yus, F. (2003). Cooperación y relevancia. Dos aproximaciones a la interpretación. Alicante: Publicaciones de la Universidad de Alicante

Zhang, Y., Dixon, T., \& Conrad, K. (2010). Female body image as a function of themes in rap music videos: a content analysis. Sex Roles, 62, 787-797.

Zimmerman, A. \& Dahlberg, J. (2008). The Sexual Objectification of Women in Advertising: A Contemporary Cultural Perspective. Journal of Advertising Research. doi:10.2501/S0021849908080094

- Sobre la autora:

María D. Brito-Rhor es Doctora en Ciencias Sociales y Jurídicas de la Universidad Rey Juan Carlos. Posee un MBA de la Pontificia Universidad Católica de Chile. Obtuvo un BSBA de la Universidad de Carolina del Norte en EE.UU. Es autora de más de 40 publicaciones.

- ¿Como citar?

Brito-Rhor, M. (2019). Uso de la imagen femenina en medios: Análisis de contenido de las portadas de revistas con presencia en redes sociales. Comunicación y Medios, (40), 128-138. 